efforts are necessary on our part to prevent the extinction of the cultural variation among chimpanzee communities that we have so recently begun to uncover.

Tetsuro Matsuzawa is at the Primate Research Institute, Kyoto University, Kanrin,

Inuyama-city Aichi 484-8506, Japan.

\section{Science in court}

\section{Laws of Men and Laws of Nature: The History of Scientific Expert Testimony in England and America by Tal Golan \\ Harvard University Press: 2004. 336 pp.

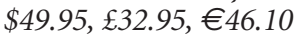

\section{Sheila Jasanoff}

Change one word - write 'trials' in place of 'laws' - and this appealingly readable book would just as appropriately be titled Trials of Men and Trials of Nature. For trials are the stuff of Tal Golan's engaging narrative as he briskly guides his readers through some of the formative moments in a century or so of scientific expert testimony in English and American common law. Men's wits and character are on trial throughout these cases, as experts from varied fields vie to position themselves, their skills and their specialist knowledge at the service of the courts. Nature, too, is often on trial, for the outcomes in the cases that Golan skilfully dissects usually turn on who is right about the way the world works, whether in explaining the silting up of a harbour on the North Sea coast of Norfolk, distinguishing human from animal blood, displaying an X-ray picture of a badly set bone, or diagnosing, through bodily measurements, the likely truthfulness of a witness's testimony in a murder trial.

On one level, Golan's well-chosen selections from the annals of nineteenth-century litigation confirm contemporary prejudices about the relationship between science and law. As in most bad marriages, encounters between the two professions seem unavoidable and yet are sources of profound miscommunication. Since the early days of the Industrial Revolution, there has been no issue so arcane, nor claim so untenable, that an expert cannot be found to help defend it in court. Experts are available for hire in cases ranging from disputes over land use and environmental degradation to criminal identification, medical malpractice and the insanity defence.

But more knowledge does not necessarily mean more illumination. The common law's adversarial genius can divide entire communities of knowledge-holders into opposing camps, each seemingly more interested in its side winning than in arriving at the truth. The notion of science as a disinterested factfinding practice flies out of the courtroom window as floods of expert testimony frustrate judges, confuse juries and make trial outcomes increasingly unpredictable. With experts dominating litigation, laws — natural or human-made - seem less and less relevant to dispensing justice.

Golan on the whole shares the sense of deepening crisis that has gripped AngloAmerican courts since the advent of professional expert testimony. "Alas," he repeatedly exclaims, as he recounts one story after another in which unresolvable battles between partisan experts took over from any impartial attempt to discern the facts of the case. As a historian, Golan is not primarily concerned with solutions, but he does not hide his yearning for a more orderly process in which judges would proactively scrutinize, and perhaps exclude, expert claims, while juries would be selected on the grounds of technical competence rather than generic civic capacity. In this spirit, he approves of the US Supreme Court's 1993 decision in the case of Daubert v. Merrell Dow Pharmaceuticals, a lawsuit over birth defects allegedly caused by the drug Bendectin, which roundly affirmed the duty of federal judges to act as gatekeepers in relation to expert testimony. Judges, the Daubert case declared, should screen expert evidence in accordance with scientists' criteria for determining whether proffered testimony is based on reliable theories and methods. Judges, in short, were asked to think like scientists - and, in so doing, to keep unreliable evidence away from overly credulous juries.

Unfortunately, as Golan's book demonstrates, the problem of expert testimony is too complicated to be solved through the simple expedient of substituting judges for juries. The historical cases impressively reconfirm a point often made by scholars of science studies: the science that courts need, along with the methods for generating it, frequently evolves under the prod of litigation, as part and parcel of the adversary process. Courts in technology-intensive societies are as much agents for producing new knowledge as sites for applying what is already known. Facts are generated, often under severe material and temporal constraints, to fill in gaps in available knowledge and to address the uncertainties of actual cases. Judges, then, may go seriously astray in excluding such evidence because it does not meet the standards of established science. Indeed, because Daubert-like challenges tend to favour corporate defendants more than plaintiffs, exclusion-minded judges may turn out in practice to be thinking more like corporations than like disinterested scientists.

What will happen if the law's dependence on expertise intensifies still further? Golan hopes that salvation will come from within the legal system - and in an unexpected way his wish may be granted. The trial itself may gradually yield to methods of dispute resolution that turn less on the theatrics of the adversary process. Litigation statistics in the United States suggest that trials are becoming a thing of the past, a consequence no doubt of spiralling costs, of which expert testimony is a not inconsiderable fraction. But are backroom bargains, out-of-court settlements and sealed court records desirable substitutes for litigation? This is a question that those committed to both truth and justice may reasonably ask.

Sheila Jasanoff is professor of science and technology studies, John F. Kennedy School of Government, Harvard University, Cambridge, Massachusetts 02138, USA.

\section{Sizing up the world}

\section{Measurement Theory and Practice: The World Through Quantification}

by David J. Hand

Hodder Arnold: 2004. 320pp. £45, \$60

\section{Stephen Senn}

Measurement theory provides a similar touchstone in science to linguistic theory in philosophy. Some see it as fundamental, others as trivial. Most scientists regard it as a distraction, as they seek to theorize and measure, but not to theorize about measurement. It is surprising how many statisticians are largely indifferent to the nature and purpose of measurement. To be sure, there are many statistical theories of errors in measurement, and plenty about probability, but these are not the same as theories about measurement itself. Statisticians have

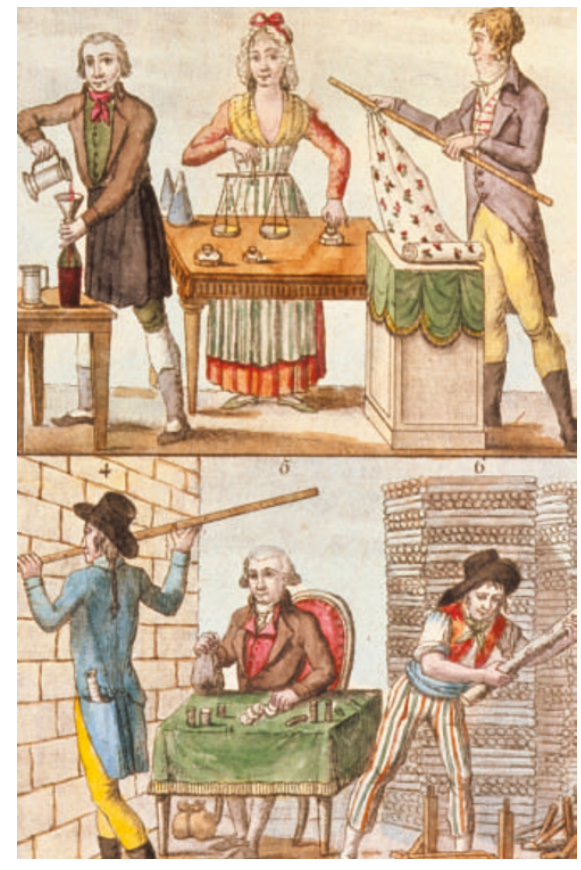

A measured approach: France adopted the metric system in the late eighteenth-century. 


\section{A medical history}

Whether your interest lies in anatomy, pathology, surgery or the history of science, or, like myself, you are just curious, the reopening last month of the Hunterian Museum at the Royal College of Surgeons of England in London is an event to be celebrated.

Although only 3,500 of the Hunterian's collection of some 65,000 items survived the bombing of the museum in 1941 (right), the remainder of this great eighteenth-century 'cabinet of curios' still ranges over an extraordinary and wonderful breadth of natural science. From the treatment of gunshot wounds and syphilis, through the anatomy of the extinct giant deer, to tooth transplants, the life cycle of bees and a dissection of a coachman's leg (below right), there is something for everyone in this amazing collection, which has undergone a £3.2-million (US\$6-million) refurbishment.

The museum's founder, John Hunter (1728-93), was one of three brothers from Scotland who sought fame and fortune as surgeons in London. William, the eldest, was already well established when John joined him as an apprentice in 1748. After a career as an army surgeon, John married the talented Anne Home, who established a fashionable salon that attracted the great and the good of the day, from James Boswell to Joseph Banks. John was a workaholic who became successful as a surgeon, pathologist, teacher and experimentalist, and helped to lay the foundations of modern medicine. This is suitably celebrated by the excellent new displays put together by curator Simon Chaplin and his team. William Hunter's collection is at the Hunterian Museum in Glasgow.

www.rcseng.ac.uk/services/museums
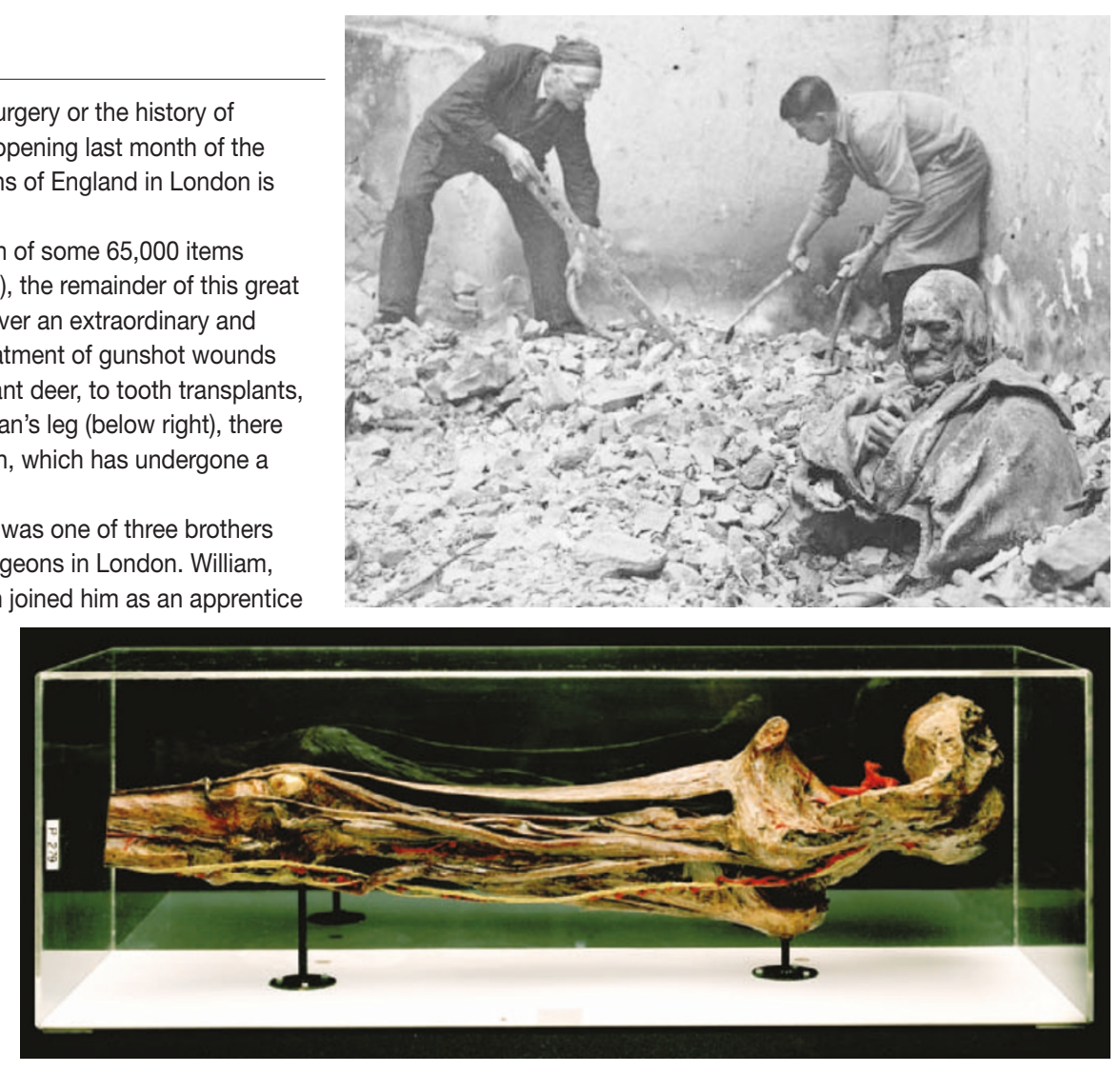

a tendency to limit their contributions in research collaborations to advising or determining how measurements should be analysed, and how many should be taken, rather than what the measurements should be. Even in the field of experiment design, the emphasis is on choosing patterns of inputs to the experiment, rather than advising on the measurement of outputs.

My field is medical statistics and although I take some measurement issues seriously, I shy away from others. I always find, for example, that whenever I have anything to do with quality of life, mine suffers and I avoid thinking about it accordingly. An honourable exception among statisticians is David Hand, who originally trained as a mathematical physicist. Since his conversion to being a statistician he has worked in psychology and medicine, as well as on economic and financial topics such as credit scoring. Hand, who is professor of statistics at Imperial College London, has been worrying about issues concerning measurement for years and has now written this thought-provoking monograph.

There are two different sorts of chapter in the book. The first four cover matters of fundamental importance for all sciences: a general introduction is followed by discussions of the nature and process of measurement and accuracy. The last five chapters cover various sciences - psychology, medicine, the physical sciences, economics and the social sciences - and include a final remain- der chapter to sweep up all terms not covered by the preceding expansion. My one major criticism is that there isn't a chapter on statistics itself: there are just three pages on probability in the final chapter. More could have been said about this. For example, is measure theory fundamental or a fundamental mistake as maintained by Glen Shafer and Vladimir Vovk in their book Probability and Finance (Wiley, 2001)? Other omissions include any discussion of the measurement of political preferences and, for example, Condorcet's paradox and Arrows' impossibility theorem and their implications for the impossibility of perfect voting systems.

However, the book is full of wonderful things. Here is Hand writing about Luce's principle governing the classes of possible relationships between variables, which has implications as to the sort of scientific laws that are possible: "To me, when I first heard of the idea and saw its implications, it seemed remarkable, lending extraordinary power to the search for scientific laws." I have also now had such a revelation, but its source was Hand's book and the valuable discussion of Luce that it contains, both in chapter 2 (whence the quote) and later in chapter 7 on the physical sciences. This latter chapter also has excellent discussions on dimensional analysis and the implications for regression coefficients.

Hand also sheds light on the baffling and notorious 'two-envelopes puzzle' (also known as the 'exchange paradox'). You are given a choice of two envelopes and reliably informed that one contains twice as much money as the other. Having picked one, but not yet opened it, you argue: "If I exchange, I double my money with a probability of one-half, and halve it with probability of one-half, and since half of two plus half of a half is one-and-a-quarter, my expectation is greater if I exchange." Having exchanged, you can then use the same argument to change back again.

Many other matters are expertly touched on too. To pick some, not at all at random, I found the discussions of the various forms of indirect scaling, of psychophysics, of indices in economics, and on league tables particularly interesting, and will find much of what is in the chapters on medicine and psychology useful in my work. The book is also pleasantly sprinkled with historical observations, interesting quotations and anecdotes. For instance, we learn of Claude Litre, born in Margaux in the heart of the Medoc (whose name speaks volumes, but of fiction in this case).

This book ought to be on every statistician's shelves and on those of many other scientists as well. The author concludes that "measurement is what distinguishes the civilized from the uncivilized". He is to be congratulated for this stimulating contribution to civilizing his fellow scientists.

Stephen Senn is in the Department of Statistics, University of Glasgow, Glasgow G12 8QQ, UK. 